\title{
Neural and endocrine effects on classical conditioning: A comparison of ACTH and hippocampectomy
}

\author{
RICHARD L. PORT, ADEL A. MIKHAIL, MARTHA A. KLINE, \\ and MICHAEL M. PATTERSON \\ Ohio University, Athens, Ohio
}

\begin{abstract}
The effects of bilateral hippocampal lesions and systemic elevation of ACTH were compared using the classically conditioned rabbit nictitating membrane response. Animals with hippocampal lesions and unoperated animals that received ACTH (5 I.U. $/ \mathrm{kg}$ ) exhibited a facilitated rate of acquisition and decreased conditioned response onset latency relative to normal control groups or animals with cortical lesions. The administration of ACTH did not alter performance in animals with hippocampal damage, indicating that the effects of these treatments are not additive. The performance of a second group of animals that was treated with a smaller dosage of ACTH (2.5 I.U./kg) was no different from that of any other group, suggesting a dose-dependent effect of the hormone. The selective replication of hippocampal deficits ascribed to a loss of response modulation suggests that ACTH may influence learning by stimulating hippocampal neurons.
\end{abstract}

Recently, we have proposed that hippocampal participation in behavioral plasticity involves two distinct processes (Port, Mikhail, \& Patterson, 1985). Initially, the hippocampus provides a neuronal representation of the temporal characteristics of environmental stimulation, a "stimulus map." Later, a "neural model"' of the learned behavioral response develops within the hippocampal multiple-unit activity. The "stimulus map" appears to provide a substrate for the association of sensory events, while the "neural model"' may modulate temporal aspects of learned behavior.

The encoding of stimulus parameters, including duration and modality, by hippocampal neurons has been well documented by Vinogradova (1975). Presumed loss of this information, in hippocampally lesioned subjects, appears to preclude learning that is devoid of motor activity. Sensory preconditioning, an association of two conditional stimuli, has been shown to be abolished by fimbrial damage (Port \& Patterson, 1984). Latent inhibition, the retardation of acquisition by stimulus preexposure, is also abolished by hippocampal damage (Solomon \& Moore, 1975). Additionally, the effect of hippocampal damage on discrimination reversal learning appears to be related to "learning not to respond" to a previously reinforced CS (Berger \& Orr, 1983). Thus, the hippocampus appears

The research presented here was supported by National Institute of Neurological and Communicative Disorders Grants NS10647 and NS14545, the American Osteopathic Association Bureau of Research Grant 81-80-023, and the Ohio University College of Osteopathic Medicine. We would like to express our appreciation to Natalie Joy and Beth Portanova for their assistance in pilot studies that preceded this experiment. R. L. Port and A. A. Mikhail are in the Department of Psychology; M. A. Klein is in the Department of Chemistry. Requests for reprints should be addressed to Michael M. Patterson, College of Osteopathic Medicine, Ohio University, Athens, $\mathrm{OH} 45701$. necessary only in the absence of (reflexive) motor activity.

A temporal "neural model" of the learned motor response was first described by Berger, Alger, and Thompson (1976). An analysis of hippocampal multipleunit activity during classical delay conditioning of the rabbit nictitating membrane (NM) response revealed a learning-dependent increase in pyramidal cell activity. Later studies have shown a near-perfect correlation between amplitude and the time course of the neural and behavioral responses (Berger \& Thompson, 1978) and that the neural response shifts earlier in training than does the behavioral response when the interstimulus interval (ISI) is altered (Hoehler \& Thompson, 1980). The impact of hippocampal lesions on associative learning that involves motor responding appears to be relatively subtle. A facilitation of acquisition has been reported in both operant (Duncan \& Duncan, 1971; Isaacson, Douglas, \& Moore, 1961) and classical (Schmaltz \& Theios, 1972) paradigms. An analysis of hippocampal-lesion/ISI interactions (Port et al., 1985) has indicated that facilitation of classical conditioning may occur only when the ISI is less than optimal (see Gormezano, Kehoe, \& Marshall, 1983). Hippocampally lesioned animals acquired CRs more quickly than cortically lesioned or unoperated controls when short $(150-\mathrm{msec})$ or long $(600-\mathrm{msec})$ ISIs were employed. With an optimal (300-msec) ISI, hippocampal subjects learned at rates no different from those of controls. Thus, the involvement of the hippocampus may be related to temporal demands of the task. An alteration of response onset latency has also been found in hippocampally damaged animals (Port \& Patterson, 1984; Port et al., 1985). Consequently, as suggested by Solomon (1979), the hippocampus appears to exert a rather subtle influence on the acquisition of classically conditioned responses.

The facilitation of acquisition and alteration of response 
timing in classical conditioning can both be addressed in terms of a modulatory influence of the temporal model on learned behavior. Under optimal temporal conditions, little or no modification of the response may be required. The latency of the $C R$ would be roughly equivalent to the predisposition of the basic neural substrate involved in associative plasticity. When the ISI is relatively short or relatively long, the temporal model may modulate the "hard-wired" motor response to ensure that the characteristics conform to the stimulus configuration. Conceptually, when modulatory activity is increased, the behavioral expression of an association may be slowed. Thus, loss of the modulatory signal (in hippocampally lesioned animals) could produce a faster expression of learning, but at the expense of precise response timing.

Others (Lovely, 1975; Pagano \& Lovely, 1972; Woodruff \& Kantor, 1983) have suggested that the deficits found in hippocampally lesioned animals may be attributable to a secondary change in hormonal levels rather than to a loss of hippocampal processes. Mason's (1957) report of decreased levels of ACTH following stimulation of the hippocampus led to speculation that hippocampal damage might produce chronic elevation of ACTH levels. Analysis of plasma levels of ACTH or associated steroids in hippocampally damaged animals has produced reports of both elevated (Fendler, Karmos, \& Telegdy, 1961; Knigge, 1961) and normal (Coover, Goldman, \& Levine, 1971) levels.

The notion that deficits found in lesioned animals could be mediated hormonally was formally proposed by Montgomery, Berkut, Grubb, and Westbrook (1971). Citing the relationship between the hippocampus and ACTH secretion, Pagano and Lovely (1972) sought to evaluate the viability of this hypothesis in regard to hippocampal facilitation of shuttlebox avoidance learning. Their results indicated that ACTH injections also facilitated acquisition and that the performance of normal animals was influenced by the diurnal cycle of the hormone. Lovely (1975) has found that hypophysectomy, which depletes the organism of ACTH, deters facilitation of shuttlebox avoidance in hippocampally lesioned animals but not in septally lesioned subjects. However, the metabolic derangement and physical weakness that accompany removal of the pituitary (de Wied, 1974) make interpretation of these findings quite difficult.

Many studies have demonstrated a striking parallel between the effects of hippocampal lesions and elevation of ACTH. The increased resistance to extinction of avoidance responding found in hippocampal animals (Isaacson et al., 1961) has also been demonstrated in ACTH-injected animals (Murphy \& Miller, 1955). The deficit in spontaneous alternation that has been observed in hippocampally lesioned animals (Roberts, Dember, \& Brodwick, 1962) has been replicated via elevation of ACTH as well (File, 1978). Ultimately, the notion that the effects of the neural and endocrine manipulations could involve a common substrate appears tenable.

An earlier study (Port \& Patterson, in press) found that elevation of ACTH had no significant effect on sensory preconditioning. Therefore, it was postulated that ACTH elevation might selectively mimic deficits ascribed to the "neural model." Facilitated acquisition and altered response topography in classical conditioning are among the deficits associated with a loss of the "neural model." The present study is a comparison of the performance of hippocampally lesioned and ACTH-injected animals in delay conditioning. An analysis of dose-dependent effects and hormone-lesion interaction was included to determine if a common mechanism was likely.

\section{METHOD}

\section{Subjects}

The subjects were 48 experimentally naive male and female New Zealand White rabbits. The animals weighed between 2.2 and $2.8 \mathrm{~kg}$ and were individually housed with ad-lib access to food and water. All procedures were carried out during the light portion of a 12$/ 12-\mathrm{h}$ light/dark cycle. Six subjects were assigned randomly to each of the following groups: hippocampally lesioned $(\mathrm{H})$, cortically lesioned (C) nonoperated $(\mathrm{N})$, two groups of ACTH-elevated animals-one receiving $2.5 \mathrm{I}$.U./kg body weight (A1) and the other $5.0 \mathrm{I} . \mathrm{U} . / \mathrm{kg}$ body weight (A2)-sham-injected nonoperated (N-SI), sham-injected hippocampally lesioned (H-SI), and hippocampally lesioned ACTH-injected (5 I.U./kg body weight) (HA).

\section{Surgery}

The surgical procedure has been described in detail elsewhere (Port, Mikhail, \& Patterson, 1985). Briefly, bilateral aspiration lesions were produced under fluothane (Halothane) anesthesia with the use of a vacuum pump. In cortical animals, neocortical tissues overlying the hippocampi were ablated; in hippocampal animals, the hippocampus was visually located and extirpated. Lesion sites were filled with gel-foam, and the bone flaps were sealed with bone wax. The wounds were treated with nitrofurazone (Furacin) and sutured. The animals were permitted 18 to 21 days to recover. Upon completion of training, the lesioned subjects were euthanized with sodium pentobarbital (Nembutal) and perfused via the carotid arteries with physiological saline followed by $10 \%$ formalin. The brains were removed and coronal sections examined to verify lesion placement. Animals with inaccurate lesions were replaced.

\section{Procedure}

The NM preparation (Gormezano, 1966; Gormezano, Schneiderman, Deaux, \& Fuentes, 1962) and conditioning apparatus (Port \& Patterson, 1984) have been described in detail previously. In brief, during training, subjects were restrained in Plexiglas boxes inside unlit, soundproof chambers. NM movement was monitored with the use of minitorque potentiometers. Stimulus delivery and data collection were controlled by an Apple II/FIRST computer system (Scandrett \& Gormezano, 1980). The CS was a 90-dB tone; the US was a 2-mA ac shock to the periorbital region. White noise $(72 \mathrm{~dB})$ was present at all times during training.

Initially, all subjects underwent a 30 -min adaptation session in the conditioning apparatus. Training began on the following day, and each session consisted of 27 reinforced and 3 nonreinforced (test) trials. Daily sessions continued for 5 consecutive days. A CS duration of $200 \mathrm{msec}$, a US duration of $50 \mathrm{msec}$, and an ISI of $150 \mathrm{msec}$ were used. Responses occurring after CS onset and prior to US onset were classified as CRs. Responses during the CS on test trials were classified as CRs. The intertrial interval was random, with a mean of $45 \mathrm{sec}$.

Subcutaneous injections were given approximately $5 \mathrm{~min}$ prior to each session. Subjects in Groups A2 and HA were injected with 5 I.U. of adrenocorticotrophic hormone (Sigma, Grade V) per kilogram body weight, suspended in $1 \mathrm{ml}$ of vehicle. Animals in Group A1 received $2.5 \mathrm{I} . \mathrm{U} . / \mathrm{kg}$ suspended in $1 \mathrm{ml}$ of vehicle. 
Animals in Groups N-SI and $\mathrm{H}$-SI received $1 \mathrm{ml}$ of vehicle alone. Subjects in Groups $\mathrm{H}, \mathrm{N}$, and $\mathrm{C}$ were not injected.

\section{RESULTS}

\section{Histology}

Four hippocampally lesioned subjects failed to survive the surgery and were subsequently replaced. One subject was found to have significant damage to the septal area and was also excluded. The 18 animals in the hippocampal groups were all found to have bilateral damage, which typically began near the fimbria and extended in a posterior direction for at least $10 \mathrm{~mm}$. The dorsal fornix was also transected. No damage to the thalamic region or other adjacent structures was detected. Cortical subjects were found to have sustained damage that was restricted to the neocortex and approximated the hippocampal damage in an anterior-posterior plane. Figure 1 is a reconstruction of damage sustained by lesioned subjects.

\section{Behavioral}

Percent CRs were analyzed over training using analysis of variance (ANOVA). A significant effect of session $[F(4,160)=175.9, p<.01]$ was presumed to reflect learning. A significant effect of group $[F(7,40)=2.57$, $\mathrm{p}<.05$ ] was evaluated using Tukey's honestly significant difference (HSD) test $(\mathrm{p}<.05)$. Groups HA, A2, $\mathrm{H}-\mathrm{SI}$, and $\mathrm{H}$ had significantly greater mean percent CRs than Groups N, N-SI, and C. No other difference was significant. The interaction was nonsignificant. Response rates were plotted over training and are presented in Figure 2.

Mean response onset latency for Sessions 3 through 5 was analyzed with ANOVA. The group effect $[\mathrm{F}(7,40)$ $=4.77, \mathrm{p}<.01]$ and session effect $[\mathrm{F}(2,80)=8.25$, $\mathrm{p}<.01]$ were significant. The interaction was nonsignificant. The session effect appeared to reflect learning,
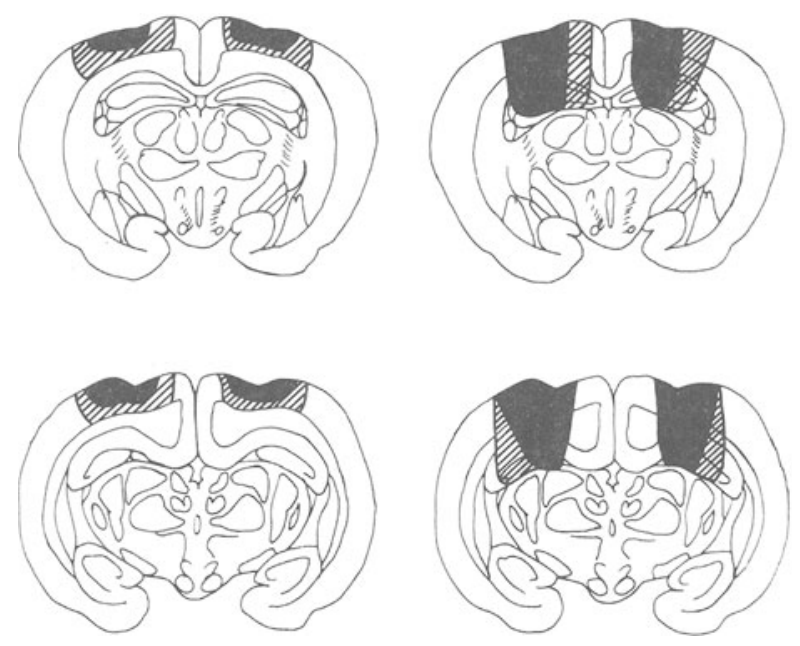

Figure 1. Reconstructions of the least extensive (solid) and most extensive (striped) damage present for subjects in the cortical (left) and hippocampal (right) lesion groups. with response onset shortening over training. The group effect was analyzed using Tukey's HSD $(p<.05)$ test. Groups HA, H, H-SI, and A2 were found to have significantly shorter mean response onset latency than Groups N, N-SI, and C. No other differences were significant. Onset latency was plotted over training and is presented in Figure 3.

Mean response peak latency was analyzed for nonreinforced (test) trials with ANOVA. The group effect, session effect, and interaction were nonsignificant.

\section{DISCUSSION}

The results of the present study indicate that elevated levels of ACTH and lesions of the hippocampus produce similar effects in classical delay conditioning. A facilitation of acquisition and altered response onset latency were exhibited by normal subjects receiving 5 I.U./kg ACTH and subjects with hippocampal lesions. In contrast, the performance of cortically lesioned animals approximated the untreated group. ACTH effects appeared to be dosedependent in that the animals injected with $2.5 \mathrm{I} . \mathrm{U} . / \mathrm{kg}$ responded at rates and latencies roughly midway between the sham-injected and the 5-I.U./kg groups. Although a failure to find an additive effect in the ACTH-injected hippocampally lesioned group could reflect a "ceiling effect," the possibility of a common mechanism also remains viable.

Two interpretations are plausible for a common mechanism subserving the hormonal and lesion effects. The notion that the effects are mediated by increased levels of ACTH is critically dependent upon a chronic elevation of the hormone in hippocampally lesioned animals. A brief review of the available literature pertaining to levels of ACTH in hippocampally damaged animals revealed the following. All analyses of adrenocortical response to stress in hippocampal animals indicated normal levels (Coover et al., 1971; Jackson \& Regestein, 1974; Knigge, 1961; Lanier, Van Hartesveldt, Weiss, \& Isaacson, 1975; Nakadate \& de Groot, 1963; Wilson \& Critchlow, 1973). Most analyses of basal levels also were within normal limits (Coover et al., 1971; Jackson \& Regestein, 1974; Kearley, Van Hartesveldt, \& Woodruff, 1974; Lanier et al., 1975; Lengvari \& Halasz, 1973; Wilson \& Critchlow, 1973). Those studies reported elevated basal levels of either ACTH or corticosterone generally involved assays conducted relatively soon after surgery (Moberg, Scapagnini, de Groot, \& Ganong, 1971; Nakadate \& de Groot, 1963). However, two early studies (Fendler, Karmos, \& Telegdy, 1961; Knigge, 1961) reported elevated levels as late as 3 months after surgery. Woodruff and Kantor (1983) have reported elevated levels of ACTH in fornix-lesioned subjects after shuttlebox avoidance training despite stress-induced and basal levels that appeared normal. Although the issue is far from settled, the role of the hippocampus in ACTH regulation appears to be less important than previously conjectured. A review of corticosteroid inhibition of ACTH secretion by Keller- 
Wood and Dallman (1984) points out that many other structures, including the mesencephalic reticular formation, thalamus, and septum, have been implicated in ACTH regulation. Noting that hippocampal corticosterone binding sites are of extremely limited capacity, they suggest that "hippocampal corticosterone binding sites are probably not directly important in the regulation of ACTH secretion by circulating corticosteroids."

Pfaff, Silva, and Weiss (1971) have demonstrated an excitatory effect of ACTH on hippocampal pyramidal neurons. Since electrical stimulation of the hippocampus produces the facilitation of acquisition (Prokasy, Kesner,

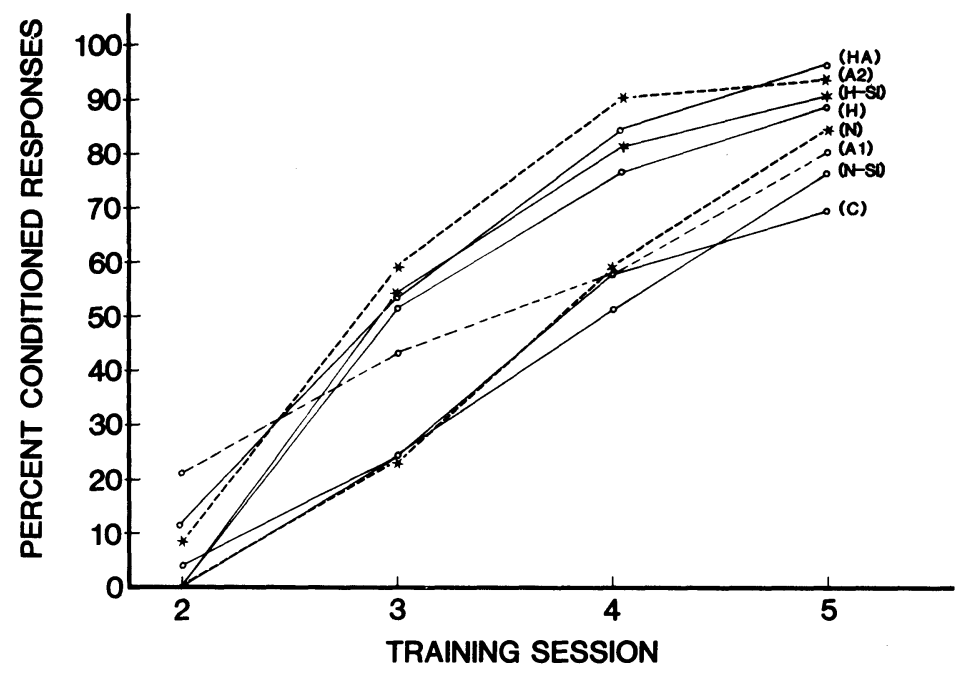

Figure 2. Response rates plotted over training for the cortical (C), sham-injected nonoperated (N-SI), nonoperated (N), ACTH-injected, 2.5 I.U./kg (A1) and 5 I.U./kg (A2), hippocampal (H), sham-injected hippocampal (H-SI), and ACTHinjected hippocampal (HA) groups.

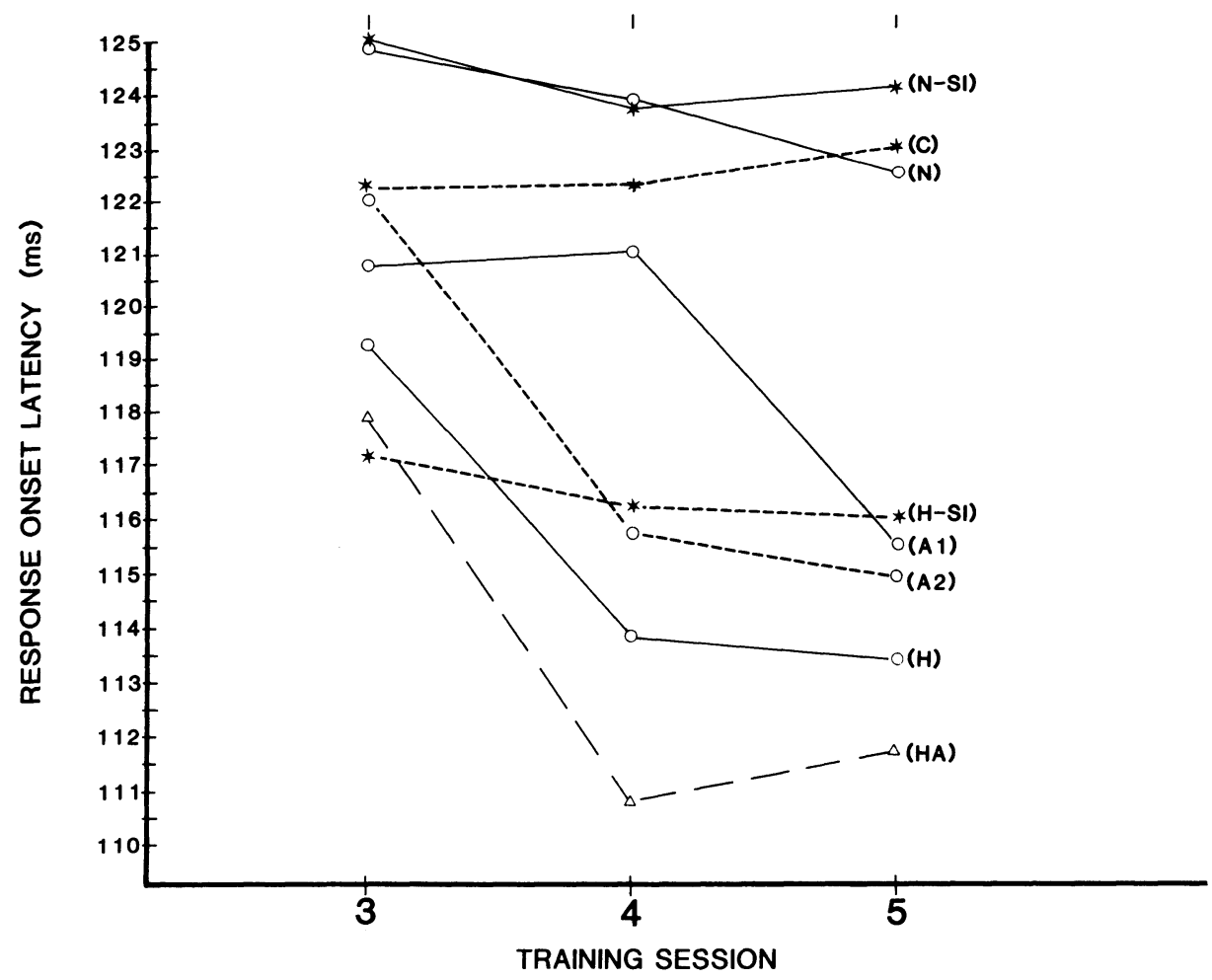

Figure 3. Response onset latency (in milliseconds) plotted over the final three training sessions for cortical (C), sham-injected nonoperated (N-SI), nonoperated (N), ACTH-injected, 2.5 I.U./kg (A1) and 5 I.U./kg (A2), hippocampal (H), sham-injected hippocampal (H-SI), and ACTH-injected hippocampal (HA) groups. 
\& Calder, 1983) that we attribute to the loss of the "neural model," it is possible that chemical stimulation operates in a similar manner. Pyramidal neurons have been identified as the source of the modulatory signal or "neural model" (Berger, Rinaldi, Weisz, \& Thompson, 1983).

That ACTH might disrupt learning processes involving the hippocampal "neural model" (i.e., classical delay conditioning) yet have no apparent effect on learning that relies on the hippocampal "stimulus map" (i.e., sensory preconditioning) is explicable in terms of the physiological aspects of each process. The "neural model" involves a dynamic representation of temporal characteristics of how a response should occur. The "stimulus map" is a relatively passive process; the input from the entorhinal region is relayed virtually as received. Therefore, it is quite reasonable that the stimulatory effect of ACTH on hippocampal neurons might selectively impede the dynamic component but not the passive component of hippocampal functions.

At present, it is at least conceivable that the similar effects of the two manipulations may be due to ACTH stimulation of hippocampal cells. Further study, including analyses of hippocampal unit activity during learning in ACTH-elevated subjects and infusion of ACTH directly into the hippocampal formation during learning, may supplement our understanding of the processes underlying these manipulations.

\section{REFERENCES}

Berger, T. W., Alger, B., \& Thompson, R. F. (1976). Neuronal substrate of classical conditioning in the hippocampus. Science, 192, 587-589.

Berger, T. W., \& ORR, W. B. (1983). Hippocampectomy selectively disrupts discrimination reversal conditioning of the rabbit nictitating membrane response. Behavioral Brain Research, 8, 49-68.

Berger, T. W., Rinaldi, P. C., Weisz; D. J., \& Thompson, R. F. (1983). Single-unit analysis of different hippocampal cell types during classical conditioning of rabbit nictitating membrane response. Journal of Neurophysiology, 50, 1197-1219.

Berger, T. W., \& ThOMpson, R. F. (1978). Neuronal plasticity in the limbic system during classical conditioning of the rabbit nictitating membrane response. I. The hippocampus. Brain Research, 145, 323-346.

Coover, G. D., Goldman, L., \& Levine, S. (1971). Plasma corticosterone increases produced by extinction of operant behavior in rats. Physiology \& Behavior, 6, 261-263.

DE WIED, D. (1974). Pituitary-adrenal system hormones and behavior. In F. O. Schmitt \& F. G. Worden (Eds.), The neurosciences: Third study program (pp. 653-666). Boston: M.I.T. Press.

Duncan, P. M., \& Duncan, N. C. (1971). Free operant and T-maze avoidance performance by septal and hippocampal damaged rats. Physiology \& Behavior, 7, 687-693.

Fendler, K., Karmos, G., \& Telegdy, G. (1961). The effect of hippocampal lesion on pituitary-adrenal functions. Acta Physiologica Academiae Scientarium Hungaricae, 20, 293-297.

FILE, S. E. (1978). ACTH but not corticosterone impairs habituation and reduces exploration. Pharmacology \& Behavior, 9, 161-164.

Gormezano, I. (1966). Classical conditioning. In J. B. Sidowski (Ed.), Experimental methods and instrumentation in psychology (pp. 385420). New York: Appleton.

Gormezano, I., Kehoe, E. J., \& Marshall, B. S. (1983). Twenty years of classical conditioning with the rabbit. In J. M. Sprague \&
A. N. Epstein (Eds.), Progress in psychobiology and physiological psychology (Vol. 10). New York: Academic Press.

Gormezano, I., Schneidermann, N., Deaux, E. G., \& Fuentes, I. (1962). Nictitating membrane: Classical conditioning and extinction in the rabbit. Science, 138, 33-34.

HOEHLER, F., \& THOMPSON, R. F. (1980). Effect of the interstimulus (CS-US) interval on hippocampal unit activity in classical conditioning of the rabbit nictitating membrane response. Physiological Psychology, 7, 345-351.

IsaAcson, R. L., Douglas, R. J., \& Moore, R. Y. (1961). The effect of radical hippocampal ablation on acquisition of avoidance response. Journal of Comparative and Physiological Psychology, 54, 625-628.

JACKSON, W. J., \& REGESTEIN, Q. R. (1974). Hippocampectomy in rhesus monkeys: Effects on plasma cortisol during two stressful conditions. Society for Neuroscience Abstracts, 4, 266.

Kearley, R. C., Van Hartesveldt, C., \& Woodruff, M. L. (1974). Behavioral and hormonal effects of hippocampal lesions on male and female rats. Physiological Psychology, 2, 187-196.

Keller-Wood, M. E., \& Dallman, M. F. (1984). Corticosteroid inhibition of ACTH secretion. Endocrine Reviews, 5, 1-24.

KNIGGE, K. M. (1961). Adrenocortical response to immobilization in rats with lesions in hippocampus and amygdala. Federation Proceedings, 20, 185.

Lanier, L. P., VAN HaRTesveldt, C., Weiss, B. J., \& IsaAcson, R. L. (1975). Effects of differential hippocampal damage upon rhythmic and stress-induced corticosterone secretion in the rat. Neuroendocrinology, 18, 154-160.

LengVari, I., \& Halasz, B. (1973). Evidence for a diurnal fluctuation in plasma corticosterone levels after fornix transection in the rat. Neuroendocrinology, 11, 191-196.

Lovely, R. H. (1975). Hormonal dissociation of limbic lesion effects on shuttlebox avoidance in rats. Journal of Comparative and Physiological Psychology, 89, 224-230.

Mason, J. W. (1957). The central nervous system regulation of ACTH. In H. H. Jasper, L. D. Procter, K. S. Knighton, W. S. Noshay, \& R. T. Costello (Eds.), Reticular formation of the brain (pp. 645-670). Boston: Little, Brown.

Moberg, G. P., Scapagnini, U., De Groot, J., \& Ganong, W. F. (1971). Effect of sectioning the fornix on diurnal fluctuation in plasma corticosterone levels in the rat. Neuroendocrinology, 7, 11-15.

Montgomery, R. L., Berkut, M. K., Grubb, E. F., \& Westbrook, D. L. (1971). Hormonal influence on behavior in brain lesioned male rats. Physiology \& Behavior, 7, 107-111.

MurPhy, J. V., \& MiLler, R. E. (1955). The effect of adrenocorticotrophic hormone (ACTH) on avoidance conditioning in the rat. Journal of Comparative and Physiological Psychology, 48, 47-49.

Nakadate, G. M., \& DE Groot, J. (1963). Fornix transection and adrenocortical function in rats. Anatomical Record, 145, 338.

Pagano, R. R., \& Lovely, R. H. (1972). Diurnal cycle and ACTH facilitation of shuttlebox avoidance. Journal of Comparative and Physiological Psychology, 8, 721-723.

Pfaff, D. W., Silva, M. T., \& Weiss, J. M. (1971). Telemetered recordings of hormonal effects on hippocampal neurons. Science, 172, 394-395.

Port, R. L., Mikhail, A. A., \& Patterson, M. M. (1985). Differential effects of hippocampectomy on classically conditioned rabbit nictitating membrane response related to interstimulus interval. Behavioral Neuroscience, 99, 200-208.

Port, R. L., \& PAtTerson, M. M. (1984). Fimbrial lesions and sensory preconditioning. Behavioral Neuroscience, 98, 584-589.

Port, R. L., \& Patterson, M. M. (in press). Sensory preconditioning in ACTH elevated rabbits. Physiology \& Behavior.

Prokasy, W. F., Kesner, R. P., \& Calder, L. D. (1983). Posttrial electrical stimulation of the dorsal hippocampus facilitates acquisition of the nictitating membrane response. Behavior Neuroscience, 97, 890-896.

RoberTs, W. W., Dember, W. N., \& Brodwick, M. (1962). Alternation and exploration in rats with hippocampal lesions. Journal of Comparative and Physiological Psychology, 55, 695-700.

SCANDRETT, J., \& GoRMEZANO, I. (1980). Microprocessor control and 
A/D data acquisition in classical conditioning. Behavior Research Methods \& Instrumentation, 12, 120-125.

SchmaltZ, L. W., \& Theios, J. (1972). Acquisition and extinction of a classically conditioned response in hippocampectomized rabbits. Journal of Comparative and Physiological Psychology, 79, 328-333.

Solomon, P. R. (1979). Temporal vs spatial information processing theories of hippocampal function. Psychological Bulletin, 86, $1272-1279$.

Solomon, P. R., \& Moore, J. W. (1975). Latent inhibition and stimulus generalization of the classically conditioned nictitating membrane response in rabbits following dorsal hippocampal ablation. Journal of Comparative and Physiological Psychology, 89, 1192-1203.

VINOGRADOVA, O. S. (1975). Functional organization of the limbic system in the process of registration of information: Facts and hypotheses.
In R. L. Isaacson \& K. H. Pribram (Eds.), The hippocampus: Vol. 2. Neurophysiology and behavior (pp. 3-69). New York: Plenum Press. WiLson, M., \& CrITCHLOW, V. (1973). Effect of fornix transection or hippocampectomy on rhythmic pituitary-adrenal function in the rat. Neuroendocrinology, 13, 29-40.

WoodrufF, M. L., \& KANTOR, H. M. (1983). Fornix lesions, plasma ACTH levels, and shuttlebox avoidance in rats. Behavioral Neuroscience, 97, 897-907.

(Manuscript received March 21, 1984; revision accepted for publication March 28, 1985.) 